\title{
Analysis of School Attachment among Students of a Boarding High School in Albania
}

\author{
Mehmet Aslan \\ 'Hëna e Plotë' Beder University, Tirana/ Albania \\ maslan@beder.edu.al
}

\section{Doi:10.5901/jesr.2014.v4n2p287}

\begin{abstract}
When students feel connected to school and have strong relations with their teachers and peers, they are more likely to be successful and prevent misconducts as they have more tendency in staying longer at school, spending more time with their peers and teachers which (in)directly have effects on their academic achievements. Research conducted in this study is oriented on a data of both qualitative and quantitative results obtained from 95 samples at Hafiz Ali Korca Boarding High School in Kavaje, Albania. The results of the collected data indicate that school belonging is a gradually evolving sense through students of first year to the students of last year at this specific boarding school. The study also shows that there is a strong correlation between school attachment and family, teachers, peers and facilities of the school. Data is collected through questionnaires, and two case studies which are implemented through quasi-experiment. The students chosen for case studies are of two specific problems; a) a student that had difficulties in overcoming with language barriers due to his regional background as he had to get used to a new school setting far from his family, b) a student that has to stay at school dormitory while he had his home within city, thus suffered from loneliness, and find it difficult to relate himself with school at the very beginning.
\end{abstract}

Keywords: attachment, misconduct, gradually evolving, boarding school, correlation, language barriers.

\section{Introduction}

Research conducted on the subject has been using different terminology to present the topic; attachment, bonding, connectedness, engagement, and belonging. Attachment and bonding are more commonly used, thus in this study these two will be used in general to refer the topic. Some researchers study school engagement while others examine school attachment, and still others analyze school bonding. (Libbey, 2004) Students from different regions of Albania that have to live in an educational institution, not only for school time but also for after school times as they have to live in dormitories, experience different problems and encounter myriads of factors that shape their social and psychological well beings which are definitely subject to study as in investigating factors affecting student's relation with school in terms of school bonding or attachment in Kavaje High School. Stating the importance of school attachment, one should also see the other side of the coin as alienation can be the other indicator since significant number of students may be experiencing alienation from school (Schulz \& Rubel, 2011). In this study, the factors that increase school attachment, like modern facilities, friendly atmosphere, teacher friendly orientations, family support etc. are to be investigated in one of the high schools in Albania, thus results may reflect implications for other schools of the same kind but overall generalizing may need more data from other schools in Albania as well. On the other hand, there are other studies that have reached generalized results in terms of school bonding; if students feel safe at school they tend to indicate higher performances in terms of academic achievement (Milam, Furr-Holden, \& Leaf, 2010). However, this study is quite vital in its field as educational success is correlated with school bonding and it's the first research conducted through 'Attachment Theory' in one of the boarding schools in Albania in which elements affecting students' achievements are also to be investigated as to have the findings reflected through the results of the research.

The literature reflects a consensus on the fact that student's strong relation with school are more likely to achieve success. The schools-as-communities perspective provides a popular explanation for school-disruptive behavior, stating that interpersonal bonding at school and feelings of school belonging prevent misconduct. (Demanet, et. al, 2012) When students feel connected to or have strong bonds to their schools, they are more likely to experience academic success. (Bryan et. al, 2012) The literature also emphasizes the reason behind the usage of substance as the lack of attachment. Research widely affirms that school bonding is a protective factor for adolescent substance use. That is, when youths have positive experiences and ties to school, they are less likely to participate in illegal behaviors, such as drug and alcohol use (as cited in Shears, et. al, 2006). 
The aim of this study - together with cumulative data on the subject - is to present a unique approach to school attachment through a school in Albania as objectives and research questions require. To state the importance of school connectedness in terms of cognitive-affective structures used by the child to build viewpoints of the world, self, and others (Kennedy, 2004) in providing a vital framework to comprehend the impacts of attachment, thus we shouldn't neglect the social emotional development (Kennedy, 2004) from the perspective of attachment theory as agreed by many others as well (Blum, 2002; Bryant, Schulenberg, O'Malley,Bachnian, \& Johnston, 2003; McNeely, Nonnemaker, \& Guo, Hawkins, HiU, \& Abbott, 2001).

\section{Schooling and Counseling System of the Boarding High School in Albania}

Hafiz Ali Korca is one of the five schools of 'Sema Foundation ' which is located in Kavaja, and has been actively open since 1998. Education is for 3 years, mainly based on three languages; Albanian, Turkish, and English. The science subjects are taught in English, social subjects are in Albanian and Turkish.

Counseling process and yearly planned curriculums that will help students improve their educational talents and reach academic success in Hafiz Ali Korca High School are categorized into three groups according to students' grades of $10^{\text {th }}, 11^{\text {th }}$, and $12^{\text {th }}$ parted into nine subclasses. Academic achievement and related outcomes are correlated with students' interactions with extracurricular activities in building positive relationships (Dumais, 2009a, 2009b; Fredricks \& Eccles, 2008). The plans for academic success and psychological motivational activities that aim to provide a helpful atmosphere for students, together with other material facilities such as internet, labs, and sports center are all used throughout the year with planned weekly, monthly, and finally yearly meetings. In other words, a student's improvement is observed through different perspectives which starts with his arrival at grade 10 and finishes with his departure at grade 12. For schools to succeed, they must use the best teaching technology to improve academic competence, as well as reduce the barriers to learning represented in delinquency and drug use (Catalano, et. al, 2004).

Annually revised and innovated curriculums and yearly plans are prepared respectively for each grade, subject and department. The counseling related plans are also prepared according to aforementioned criteria with a difference of inclusion of students with special talents or extra care needed students if there are any. Two fundamental pillars; education and counseling are the basics of the schooling system which are designed to adapt facilities of the school to match students' needs. Curriculum and yearly plans are prepared by department chairmen with consultation of professionals. Traditionally designed methods are

not so effective in developing conceptual understanding of the subject matter. Because traditionally designed instruction were dependent on teacher exploration without consideration of students' preconceptions (Pabuçcu, A., \& Geban, Ö. 2012). Annual activities, like periodical parents meetings of each class, picnics, summer trips to abroad and visits to historical places in certain times are mentioned in the academic calendars of the yearly plans.

One of the major flexible as well as effective activities organized by the teachers is paying visits to student's home as to make contact with parents and family members, thus improvising a more particular approach to the student's characteristic development. Family involvement in support with peers, teachers and school is one of the vital factors in strengthening students` bonding with school (Sciarra \& Seirup, 2008; Stewart, 2008; Stewart, 2003; Zaff, Moore, Papillo, \& Williams, 2003). Such a visit is not only for telling parents about their child's marks or exam results; it's also a mutual exchange of ideas in achieving student's academic success through parents involvement in terms of motivation and a second control mechanism.

\section{Analysis of Data}

The survey implemented in the study as measurement strategy is suited to the type of outcome to be measured as the intervention serves students in grades $10^{\text {th }}-12^{\text {th }}$ who demonstrate various level of attachment to school, including various outcomes depending on the types of survey questions as reflected in the table below:

Table 1: Indicates measurement strategy in obtaining data and outcome dimensions.

\begin{tabular}{|l|c|}
\hline \multicolumn{1}{|c|}{ Outcome Dimensions } & Survey Questions (question numbers) \\
\hline Feelings about being in school & $1-5$ \\
\hline Interest in learning & $6-11$ \\
\hline Attitudes towards other students & $12-16$ \\
\hline Attitudes towards teachers & $17-22$ \\
\hline \hline Questions not matching an identified outcome dimension & $23-27$ \\
\hline
\end{tabular}


The survey contains various statements about students`school life, and was implemented to 95 samples at the boarding high school in Kavaje, Albania. Reverse coded questions are 4, 10, 13, and 18. Questions 26 and 27 are used to obtain qualitative data, however $25^{\text {th }}$ question is specifically asked for students' grades. The results generally indicate a gradually evolving sense of attachment among students as $10^{\text {th }}$ grades reflect less attachment compared to $12^{\text {th }}$ graders. Positive responses among $12^{\text {th }}$ graders are up to $53 \%$ whereas among $10^{\text {th }}$ graders it is $34 \%$. Below is the figure that shows positive responses of the $10^{\text {th }}$ and $12^{\text {th }}$ graders, $11^{\text {th }}$ graders are not estimated as they weren $t$ used for overall calculation, only 2 students were included:

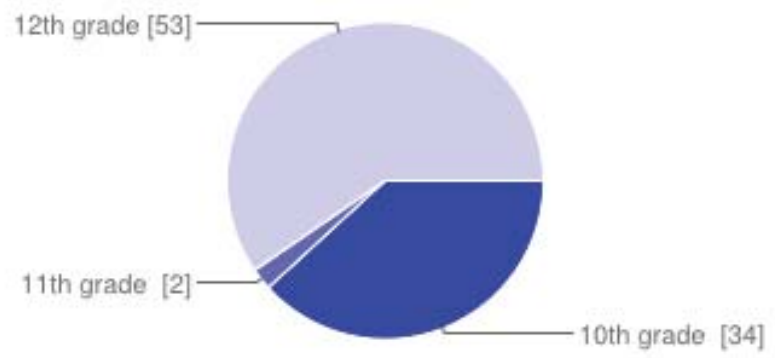

Figure 1: Indicates school attachment percentages according to their grades.

The question regarding the mentoring program of the school received highly positive responses indicating strong attachment of the students as the $26^{\text {th }}$ survey question reflects:

\section{Do you enjoy the mentoring program?}

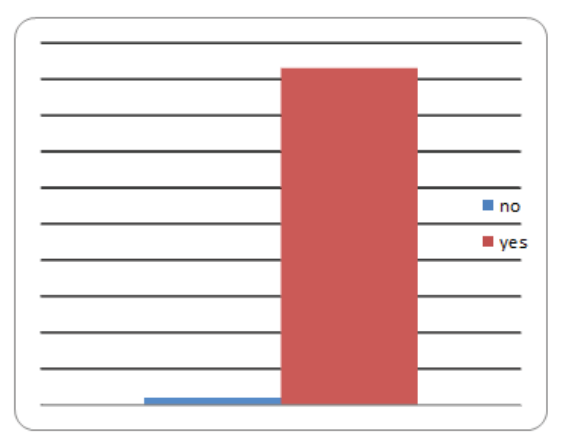

Figure 2: Indicates the significant difference in favor of 'yes` as positive response.

The highest indicator- among other obtained data- reflected in figure 2 as "yes" and "no" also demonstrates strong correlation between SEN, facilities, peers, school setting, staff and other influential elements of school attachment as it is also reflecting student's sense of safety, findings suggest that students' sense of safety may be positively linked to academic achievement through their prior academic achievement (Bryan et. al, 2012) as student's sense of safety is linked to school connectedness; "How much I like school," indicates an outcome of academic achievement; a measure of students' attachment to school, had the strongest effect on academic achievement (Bryan et. al, 2012).

Questions in the survey were mainly parted into 4 groups of different outcomes as mentioned in Table 1. Following measurements are based on one of these four dimensions. The five types of questions on student's feelings about school are to measure student's self perception in school attachment both in manners and beliefs (Maddox \& Prinz, 2003). The results obtained from the survey questions related with the feelings about school are of aforementioned five question types reflecting following numeric values: 
Table 2: Indicates percentages for 5 question types of feelings about being at School.

\begin{tabular}{|l|c|c|c|c|c|}
\hline & $\mathbf{1}$ & $\mathbf{2}$ & $\mathbf{3}$ & $\mathbf{4}$ & $\mathbf{5}$ \\
\hline Strongly Disagree & $0 \%$ & $6 \%$ & $4 \%$ & $4 \%$ & $9 \%$ \\
\hline Disagree & $20 \%$ & $13 \%$ & $7 \%$ & $9 \%$ & $10 \%$ \\
\hline Neutral & $11 \%$ & $28 \%$ & $20 \%$ & $12 \%$ & $18 \%$ \\
\hline Agree & $51 \%$ & $39 \%$ & $38 \%$ & $32 \%$ & $33 \%$ \\
\hline Strongly Agree & $37 \%$ & $14 \%$ & $31 \%$ & $43 \%$ & $31 \%$ \\
\hline
\end{tabular}

The indicators at this table are quite significant as they are reflecting students feelings about being at school, in other words the results are quite important in understanding students ' personal perceptions of their connectedness to school. Internalizing such perceptions of attachment also brings up the idea of "students in caring school communities feel that they make important contributions: hence, they are given a certain amount of influence in the school's activities and decision-making process" (Demanet, et. al, 2012).

\section{Case Study I}

Proposed Measurement Method focuses on: Change in Behavior as the student was from the northern region of Albania whose arrival to school was a big step in terms of getting involved to a very new setting of the central Albania. The preventive effect of school bonding on deviancy has been replicated by many studies (Demanet, et. al, 2012) as in this particular study we encounter one of them. He had problems of feeling connected to his peers, teachers, and personnel of the school in general as everything was new to him. His major problem was that he was also weak in English and had problems in communicating with his teachers. The preventive effect of establishing strong social and emotional connections at school on student deviancy is thus well-established in research (Demanet, et. al, 2012). Thus a change in behavior through the methodologies elaborated in the case study was expected at the end of the school year.

a. Identification of the Problem

The student I wanted to contact with was a $10^{\text {th }}$ grade student who came from Peshkopia - a far region of Albania. He had French in his previous school, and had no English private courses. When first arrived to his school in Kavaje, let alone learning a new language, he had problems in adapting to a new atmosphere where everything was new for him; school, friends, teachers, and most difficult thing for him, reported himself, was living in the dormitory as it was first time he had to stay away from his family. "Jessor and colleagues' used the phrase "positive orientation to school" to measure student attitudes and motivation toward school and learning" (Libbey, 2004).

My first contact with the student, regarding my research, was by the allowance of the school principle as I explained my reasons for asking some questions about his problems of learning English. Apart from above mentioned problems the most difficult thing for him was that he couldn`t understand the teacher as he was speaking only English during the lessons. At such a point one must follow professional approaches. "School psychologists have traditionally focused on assessment, prevention, and intervention strategies for a myriad of factors that influence school performance " (Kennedy, 2004). He also mentioned about his enthusiasm for learning English at the very beginning, but seeing the other fellow students more active and better than him caused pessimist thoughts in him which turned into lack of confidence by the time reported by his teacher regarding on his test results. Enhancement of performance based on skills such as assessment, prevention, and intervention require profound adaptive and maladaptive knowledge (Kennedy, 2004).

b. Intervention Outcomes

First and foremost, a student in a case like this, should know that it is not his fault that he fell behind the others, and he wasn't to blame for not knowing something he hadn't studied before. Student voice is an important element in enhancing teacher attachment, thus there should be "items that ask whether students can design independent projects and teachers listen to student suggestions" (Libbey, 2004). On the other hand, he should be well aware of the fact that he has to double study compared to the others, but he should take this as a motivation not a burden on his shoulders. He should also have constant contact with his teacher and be open to extra material which is for his own benefit. He should be determined in reaching the goals set by the teacher, and eager to receive more assignments, because the more he learns the better he would feel in terms of self-confidence, and he would feel pleasure from his life.

The level of the students should be considered as well as individual learning styles`as to avoid deviant peer 
influence, thus "it is noteworthy that influence occurs especially when friendship bonds with deviant peers are quite cohesive" (Demanet, et. al, 2012). but a teacher should put more emphasis on teaching the general level of the class. If the general average is intermediate, then the teacher should use a course book addressing to that level in general.

c. Teacher and Peer Attachment

A well prepared teacher in terms of lesson plans, objectives, and practices that are to be conducted in the lesson is quite essential but requires more preparation time. "School counselors should collaborate with other educational stakeholders (i.e., teachers, administrators, school staff, parents/guardians, and community members) to proactively build school commitment beliefs early in high school as well as tackle early signs of a lack of student commitment." (Bryan et. al, 2012). A good lesson should have at least three objectives in order to reach all levels of the class. The first one is to address the weak learners, another one for the average learners, and the final one for the strong learners. In other words, if you are teaching colors, main colors should be learned even by the weakest ones, some of the mixed colors should be taught to the average ones, and abstract colors could be taught to the strong learners. To eliminate deficits in learning there should be orientation programs for incoming freshmen, freshmen, sophomore students that indicate below levels in subjects they reflect deficits as to make sure students have school bonding in avoiding misconducts such as truancy, drug usage, drop outs, etc. (Bryan et. al, 2012). Assignments should also be given according to their levels and objectives set for their learning. Evaluating their homework should also be done through objectives. A teacher may feel like dividing the class into groups related their levels, but this may not be a good idea as it may cause differences to get deeper and deeper and it is against the unity of the class. Pairing the students would bring more satisfactory results in terms of learning.

d. Extracurricular Activities

An extra lesson with weaker ones is the most essential method in getting the weaker ones to reach the upper levels. Paying a visit to the family would also bring better results as parents' involvement would bring more motivation and determination. Certain parental factors are predictive of attachment security throughout development (Kennedy, 2004). A success scheme could be drawn together with family and the student. On the other hand, ups and downs are inevitable as it is a long course of study that may require even years.

e. Discussion on Case Study I

The chosen student for the case study is of those who have been suffering from aforementioned problems, but the methods elaborated in the case study could help him and his likes to overcome the problems. But involving school staff and parents would make it more practical in realizing attachment for the target students.

\section{Case Study II}

\section{a. Identifying the problem}

The student I have had contact with is a 12th grade who is supposedly getting ready for the final exam that will designate his future. His father is a businessman who is running a restaurant and has lots of fields full of grapes from where they produce wine, and have their cellar filled with different quality and type of wine.

The surprising fact is that he is quite skillful in doing what his father has been doing, and very eager in going on with the same job which may sound quite normal, but as a $12^{\text {th }}$ grade, and based on his ambitions, and father's expectations for future his motivation in studying is almost zero. His father has elevated expectations from him in terms of studying in technology of nutrition, and " him stating same thing with his father is putting me as a teacher in quite a difficult situation as I have to motivate him for the coming exam that will decide on his wanted career which requires quite hard work. " reported his Chemistry and class teacher. As to achieve beneficial outcomes in order to buffer misconducts the schools as communities should provide "a broad line of inquiry advocating that schools should be organized as caring school com-munities." (Demanet, et. al, 2012)

b. Dealing with the Problem

I asked him for a kind of interview, or let's say an invitation for a coffee to talk about his motivation and his current status in his studies. My first goal was to make him understand the vitality of the situation as he had lots of absences from class, and had very low points in exams. This case study is rather to study on the individual level of school attachment as "few studies have tested specifically whether the effects of school belonging act at the individual or the school level. " (Demanet, et. al, 2012) 
I told him about the need for studying and that he had to make some sacrifices to achieve success in his life. He agreed with me and said that he was well aware of the situation, but couldn't give up on some of his habits, like hanging out with friends, spending too much time on internet, mobile phone, and such other habits that young students at his age suffer from. He also added that he didn't need to study as he had enough money to get wherever he wanted. I told him that money is just a tool which might be shaped and used into a way of reaching our goals.

\section{c. Family involvement}

In such a case like mine, I would suggest what I did, as I wanted to have a meeting with the family to share the burden of the responsibility with the closest people in his life. The meeting went better than with what I had expected. His father was very pleased with the topics I brought up in terms of motivating him for the exam, and his future. We made an agreement on helping him by some restrictions, such as less time on the internet, no more going out without parents ' permission, and most importantly he would stay in dormitory until the end of the year as to increase cooperative learning (RE Salvin, 1980; RE Salvin, 1991) and make sure that "students from differing abilities and backgrounds are provided the opportunity to work together in teams" (Catalano, et. al, 2004).

d. Intervention Outcomes

As stated above, he had some disciplinary problems at school which were at a risky level. He had absence, low marks, and some behavioral problems against his friends and some teachers. Classroom observations and study time observations were used to enhance teacher and peer attachment in order to avoid misconducts. Involvement of students in classroom activities provides positive reinforcement for prosocial behavior, and setting clear guidelines for appropriate behavior (Catalano, et. al, 2004). I had a talk with the principles, his math's, and literature teachers as they are key subjects for the final exam. To have things under control, we decided to send reports of his exams to the family, and have the father visit him at school to check on the improvement.

\section{e. Limitation on Case Study II}

To sum up, we are still in the process of getting results as the exam will be held after two months, meanwhile I will be in constant contact with the student and the family. As of now he seems to be motivated, indicating better implications of coming to the class on time, and getting slightly better results than before. In order to achieve success, a more professional help could bring better results at the end of the year.

\section{Conclusion}

The overall results obtained through analysis of survey data, observations, and case studies indicate a high rate of school attachment at this specific boarding high school in Albania. On the other hand, the significant difference between $10^{\text {th }}$ grades and $12^{\text {th }}$ grades (53\% to $34 \%$ ) is quite essential in understanding the gradual evolving of the attachment. The majority of negative responses were given on food as the $27^{\text {th }}$ survey question (27. Is there anything else you would like to tell us about your school life?) got 17 negative responses on food out of 95 samples. The school administration may give more improtance to this results in order to decrease such beliefs and foster positive responses.

Each individual has his/her own traits, especially when it comes to teaching where differences are to be lessened or at least blurred in order to emphasis unity and reach every person in the class. On the other hand, differences are to be reflected as variety of values. Apart from above mentioned ones, some students may have had private courses and some may fall behind compared to the strong learners; some may have come from different regions of the country where teaching conditions weren 't very well; different backgrounds, gender and age differences are some of the other elements that effect students personal perceptions and their attachement to the new school. For schools to succeed, they must use the best teaching

technology to improve academic competence, as well as reduce the barriers to learning represented in delinquency (Catalano, et. al, 2004).

\section{References}

Bryan, J., Moore-Thomas, C., Gaenzle, S., Kim, J., Lin, C.-H. and Na, G. (2012), The Effects of School Bonding on High School Seniors' Academic Achievement. Journal of Counseling \& Development, 90: 467-480. doi: 10.1002/j.1556-6676.2012.00058.x

Bryant,A. L., Schulenbeig,J.E., O'Malley, R M.,Bachman, J. G., \& Johnston, L. D. (2003). How academic achievement, attitudes, and behaviors relate to the course of substance use during adolescence: A 6-year, multiwave national longitudinal study. Joumn/ of 
Research on Adolescence, 75,361-3.

Catalano, R. F., Oesterle, S., Fleming, C. B., \& Hawkins, J. D. (2004). The importance of bonding to school for healthy development: Findings from the Social Development Research Group. Journal of School Health, 74(7), 252-261.

Demanet, J., \& Van Houtte, M. (2012). School belonging and school misconduct: the differing role of teacher and peer attachment. JOURNAL OF YOUTH AND ADOLESCENCE, 41(4), 499-514.

Dumais, S. A. (2009a). The academic attitudes of American teen-agers, 1990-2002: Cohort and gender effects on math achieve-ment. Social Science Research, 38, 767-780. doi:10.1016/j.ssresearch.2009.05.010.

Dumais, S. A. (2009b). Cohort and gender differences in extracur-ricular participation: The relationship between activities, math achievement, and college expectations. Sociological Spectrum, 29, 72-100. doi:10.1080/02732170802480543.

Fredricks, J. A., \& Eccles, J. S. (2008). Participation in extracurricular activities in the middle school years: Are there developmental benefits for African American and European American youth? Journal of Youth and Adolescence, 37, $1029-1043$. doi:10.1007/s10964-008-9309-4

Guo,J.. Hawkins.J. D., HiU, K. G., \& Abbott, R. D. (2001). Childhood and adolescent predicton of alcohol abuse and dependence in young adulthood. Journal of Studies on Alcohol, 62,754-762.

Kennedy, J. H., \& Kennedy, C. E. (2004). Attachment theory: Implications for school psychology. Psychology in the Schools, 41(2), 247259.

Libbey, H. P. (2004). Measuring student relationships to school: Attachment, bonding, connectedness, and engagement. Journal of School Health, 74(7), 274-283.

Maddox, S. J., \& Prinz, R. J. (2003). School bonding in children and adolescents: Conceptualization, assessment, and associated variables. Clinical Child and Family Psychology Review, 6, 31-49.

McNeely, C. A., Nonnemaker,J. M., \& Blum, R.W.(2002). Promoting school connectedness: Evidence from the National Longitudinal Study of Adolescent Health. Journal of School Health, 72,138-146.

Milam, A. J., Furr-Holden, C. D. M., \& Leaf, P. J. (2010). Perceived school and neighborhood safety, neighborhood violence and academic achievement in urban school children. Urban Review, 42, 458-467. doi:10.1007/s11256-010-0165-7

Pabuçcu, A., \& Geban, Ö. (2012). Students' Conceptual Level of Understanding on Chemical Bonding.

Schulz, L. L., \& Rubel, D. J. (2011). A phenomenology of alienation in high school: The experiences of five male non-completers. Professional School Counseling, 5, 286-298. doi:10.5330/PSC.n.2011-14.286

Sciarra, D. T., \& Seirup, H. J. (2008). The multidimensionality of school engagement and math achievement among racial groups. Professional School Counseling, 11, 218-228.

Shears, J., Edwards, R. W., \& Stanley, L. R. (2006). School bonding and substance use in rural communities. Social Work Research, 30(1), 6-18.

Slavin R. E. (1980). Using Student Team Learning. Baltimore, Md: Johns Hopkins University.

Slavin, R. E. (1991). Synthesis of research on cooperative learning. Educational leadership, 48(5), 71-82.

Stewart, E. (2003). School social bonds, school climate, and school misbehavior: A multilevel analysis. Justice Quarterly, 20, 575-604.

Stewart, E. B. (2008). School structural characteristics, student effort, peer associations, and parental involvement. Educational and Urban Society, 40, 179-204.

Zaff, J. F., Moore, K. A., Papillo, A. R., \& Williams, S. (2003). Implications of extracurricular activity participation during adolescence on positive outcomes. Journal of Adolescent Research, 18, 599-630. 